\title{
Prospects for Achieving Sustainable Development Through the Millennium Development Goals in Nigeria.
}

By

\author{
${ }^{1}$ Akintoye Victor Adejumo and ${ }^{2}$ Opeyemi Oluwabunmi Adejumo
}

\begin{abstract}
In recent time, the concept of sustainable development cannot be overemphasized. Since the early 1980s, the term 'sustainable development' has been used widely and indiscriminately. The term began to gain popularity, when it became increasingly fashionable to use it as a way of responding to global environmental concerns, biophysical issues, fairness, equity and distribution. With this in mind, the Millennium Development Goals (MDGs) were put up in recent times to address and include the issue of sustainability in development. In essence, this study is carried out with a view to enhance the understanding about the analytical content of sustainable development as well as sensitizing the Nigerian economy to key into the current wave of sustaining the global economy. In the light of some of the environmental as well as socio-economic challenges permeating the Nigerian economy, it is therefore required that the Nigerian government concentrates on key areas that can help boost and sustain its developmental objectives. Hence, this paper helps to understand the concept and need for sustainable development. Besides, key developmental areas that require sustainability in Nigeria are addressed.
\end{abstract}

Key Words: "Sustainable”, "Globalization”, “Environment”, "Development”

\section{Introduction}

It is common knowledge within development circle that development involves a physical reality and a state of mind. Through development process, the interactions between social, economic and institutional processes must be continually sustained to meet up with increasing future demands in terms of population growth and continuous use of natural, human and material resources.

It has been observed that changes in the integrated approach to social, economic and environmental issues have not really facilitated the developmental goals in Nigeria. For

\footnotetext{
Lecturer, Department of Economics, Obafemi Awolowo University, Ile-Ife, Nigeria

2 Assistant Lecturer ,Institute for Entrepreneurship and Development Studies, Obafemi Awolowo University, Ile-If, Nigeria..
} 
instance, problems such as poverty, flooding, ethnicity, environmental pollution corruption, attitudes and lopsided income distribution have been on the increase. A cursory look at the poverty profile in Nigeria showed that in 2004, Nigeria's relative

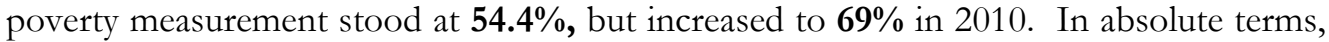
$54.7 \%$ of Nigerians were living in poverty in 2004 but this increased to $60.9 \%$ (National Bureau of Statistics, 2010). Besides these in the early 1990s Nigerian cities experienced flood hazards have more than doubled in the last ten years (Odermeho, 1993). While in recent times, it was recorded that Nigeria experienced the worst flooding as at the year 2012.

In view of these challenges, it should be recalled that in the year 2000, the Millennium Development Goals (MDGs) were adopted by 189 member countries of the United Nations including Nigeria. This was with a view to fast track key developmental issues in Nigeria which include increasing the availability of basic life sustaining goods, raising the standard of people's living as well as expanding the range of economic and social choices. A set of eight goals to be achieved by 2015 was adopted by the United Nations which were to eradicate extreme poverty and hunger; achieve universal primary education; promote gender equality and empower women; reduce child mortality; improve maternal health; combat HIV/AIDS, malaria, and other diseases; ensure environmental sustainability; and develop a global partnership for development (Todaro and Smith, 2011).

In view of these goals, it is pertinent for the Nigerian economy to understand the prospects and underlying principles for achieving these goals as well as sustaining the process of development desired. It is against this background that the study is further sub-divided into four sections. Section two takes a look at some theoretical and practical principles on sustainable development while section three reviews the plan implementation of the world summit on sustainable development. In section 4, a review of the Nigerian case on sustainable development is carried out while section five concludes the study.

\section{Literature Review- Concept of Sustainable Development}

It must be understood that there is no single definition for sustainable development but they key idea common to all definitions concerns resource exploitation at a rate that would not prove detrimental to future generations. For instance, according to the Complete A-Z Geography Handbook sustainable development is defined as "development that meets the needs of the present, without compromising future generations to meet their own needs. The environment should be seen as an asset, a stock of available wealth but if the present generation spends this wealth without investment for the future then the world will run out of resources. If, however, we use this capital to research and develop new resources for the future, we can build machines that will substitute for the environmental resource (resource substitution). A good example is the construction of solar panels to replace oil and coal"

According to the direct Government website UK "Sustainable development means a better quality of life now and for generations to come. It means not using up resources 
faster than the planet can replenish, or re-stock influences decision making with organizations, and therefore can go towards forming principles and business 'values' for example, providing information to the public in an open and accessible way and involving people and communities who are affected by those decision. Or openly reporting how they run their business and the care they take about the local environment and the people that work for them, these principles can also apply to government policies - for example, in planning regulations for green buildings and technologies. It is also about being clear and responsible about the use of scientific, and other, evidence for example, about levels of pollution or carbon emissions.

According to the international Institute for Sustainable Development (IISD) sustainable development has been defined in many ways, but the most frequently quoted definitions is form Our Common Future, also known as the Brundtland Report: "Sustainable development is development the meets the needs of the present without compromising the ability of future generations to meet their own needs. It contains within it two key concepts:

- The concept of needs, in particular the essential needs of the world's poor, to which overriding priority should be given; and

The idea of limitations imposed by the state of technology and social organization on the environment's ability to meet present and future needs".

All definitions of sustainable development require that we see the world as a system-a system that connects space; and a system that connects time. When you think of the world as a system over space, you grow to understand that air pollution form North America affects air quality in Asia, and that pesticides sprayed in Argentina could harm fish stocks off the coast of Australia. Besides, when you think of the world as a system over time, you start to realize that the decisions our grandparent made about how to farm the land continue to affect agricultural practice today; and he economic policies we endorse today will have an impact on urban poverty when our children are adults.

According to the Teachers in Development Education Annual report 2008, "Sustainable development concerns a wide range of interrelated issues which may be approached through the following seven principles or dimensions. The first concerns the interdependent nature of the word. This gives rise to the need for a participative response through the exercise of citizenship and stewardship, which is the theme of the second concept.

\subsection{The Concept of Weak and Strong Sustainability}

An implicit assumption in the constant capital rule (CCR) is that all forms of capital are substitutable for each other. On this rule, known as the weak sustainability (WS) rule, any one form of capital can be run down provided 'proceeds' are reinvested in other forms of capital. Weak sustainability does not necessarily imply that substitution is easy or inexpensive - we may have to surrender a great deal to obtain one extra unit of some forms of capital, a feature of weak sustainability that tend to be ignored by those who have criticized it. Moreover, WS requires that the running down of any form of capital is compensated by investment in some other form of capital. It is not consistent with running down capital stocks and 'consuming' the proceeds. For example, where a nonrenewable asset such as a stock of oil is being mined, WS requires that some portion of 
the revenues of this mining activity be invested in alternative assets. As a 'weak' rule, then, WS is not particularly weak, and empirical tests show that it is quite easy for a country to fail a weak sustainability test Atkinson et al (1997).

Objections to weak sustainability tend to centre on the assumed substitutability of capital stocks. Indeed, it can be argued that the philosophy of sustainable development arose precisely because there were concerns about the unsustainability of forms of economic development that sacrificed the environment in the name of economic growth. The problem can be formalized by saying that the critics regard at least some forms of capital as have no substitutes. Take the ozone layer, for example. Clearly there are some substitutes for its protective functions. Skin cancers and cataracts are one of the risks of exposure to Ultraviolent (UV) radiation in areas where the ozone layer has been 'thinned' by Chloro Fluorocarbons (CFCs). Individuals can protect themselves against these risks by wearing sun glasses and suitable clothing, as well as by changing behavior so as to avoid continued exposure. But high levels of UV radiation are also thought to interfere with immune systems and with the functioning of some important ecosystems, especially marine systems. It is far from clear what the substitute is in this context. The ozone layer may therefore have some of the characteristics of a unique asset crucial to well-being and perhaps survival. Those who believe in the non-substitutability of natural capital support strong sustainability (SS).

SS does not imply that WS is irrelevant, although some writers appear to think this. What SS requires in addition to WS is that the stocks of capital $(K)$ should not decline. 'In addition to' is needed because a situation in which natural capital is preserved but other forms of capital are allowed to decline could hardly be called 'sustainable development' (it might be 'survivable' but even that seem very unlikely). Alternatively, it might be argued that while a trade-off exists it is a bargain that most would view as highly unpalatable. This goes back to an earlier remark we made in hat WS itself does not necessarily imply that compensating for a loss of a particular asset is inexpensive.

However, many writers have criticized the sustainability approach because it assumes substitution. First, they suggest that one should to focus on weak sustainability because it creates a sense of comfort to the effect that the environment can be dispensed with, but it is hard to understand why such a discussion should preclude advocacy of strong sustainability by those who believe in it. More to the point, the preliminary evidence on weak sustainability indicators shows the potential for surprise: a large number of economies fail the weak sustainability test and if they fail that they are likely to fail any strong sustainability test (although not necessarily so), Atkinson et al (1997). Second, it is suggested that monetary indicators of constant capital fail because they use market process rather than externality-adjusted prices. But the whole point of valuing capital is to value the externalities. Whether this is done by applying shadow prices to marketed outputs or by valuing the externality, e.g. air pollution, directly, is immaterial. 
Cecelia (2009) adopted Bo Kjellen 'Diamond of Sustainability' depicted here in figure 1.

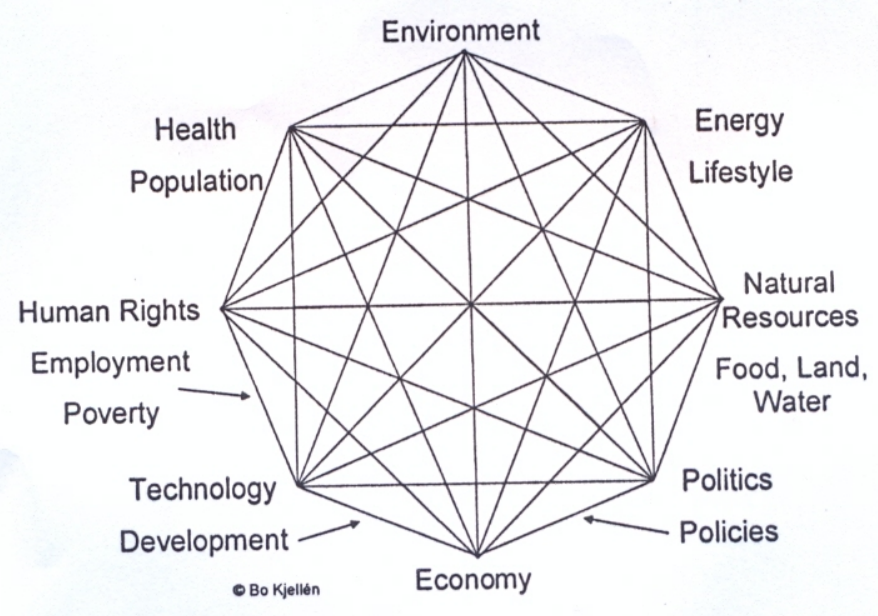

Figure 1: Kjellén Diamond of Sustainability (Kjellén, 1999)

He wrote, "(the diamond)... illustrates the fundamentals of social sciences in dealing with economic, political and social problems, the challenge now is to integrate the social sciences into developing policy focusing on long-term global sustainability." The Kjellen diamond is particularly useful as a graphical representation of the principles of sustainability. A list of principles for sustainable development is as individual as its author, but certain points appear consistently. Reading the compass points reaffirms the primary focus on social, environment and economic concerns. The diamond adds natural balance the concern for human 'resources' (social).

In the north-east quadrant, we meet the principles related to equitable sharing of natural resources and the need to encourage lifestyles of responsible consumption to ease the burden of each person's ecological footprint). In the south-east quadrant, one finds the principles related and engender respect for biological and cultural systems of the planet that sustain all life. Sustainable policies should ensure that natural resources are not depleted and engender respect for biological and cultural diversity. Moving clockwise to the south-west quadrant, we enter the domain of man-made system. Equitable distribution of knowledge and information, and equitable working conditions for those who create products and services drive these principles. Finally, in the north-west quadrant, the principles are concerned with the quality of life measured in access to food, land, water, clean air and medical attention. The diamond is one of numerous frameworks that provide guidance for communication and activity in the progress toward sustainable development.

\subsection{An Overview of Existing Literatures on Sustainable Development}

CECILIA Haskins (2009) in a paper "Using the concept of sustainable development to encourage corporate responsibility in small enterprise" employed the "Diamond of sustainability" principle which entails the principles of sustainability to focus on social, 
environment and Economic Issues as to how they affect sustainable development in the discharge of corporate social responsibility. In the progress towards sustainable development Awareness, Application, Integration and Leadership issues must be entailed in the drive towards sustainable development. With reference to a particular study of the Verdal industrial park (VIP) Aker Kvaerner, that deals in the supply of tunkey projects, niche products and specialized services in the offshore industrial area in the North Sea encountered vital challenges in it business due to but change in the market conditions in the oil production industry. They later encountered improvement in business by given alternative services through internal department within the park, For the sustainable growth of VIP, a project was conducted in four phases: first a survey was designed with the guidance of the park managers for the VIP; second the survey was distributed after a kick-off meeting describing its goals to the target audience; namely, the CEOs of the industries of VIP: third, the result survey were validated by interviews analysed and presented to the VIP community and other stake holders, fourthly, a brainstorming session was conducted to great a future vision for the VIP. They concluded that firms in VIP are a very good place to work as they are particularly concerned about economic an environmental performance. Based on this sampling, respondents appear to have a minimal awareness of the concept of eco-efficiency, But their eco-performance is probably better based on response from the interviews. A simple dashboard for plotting self assessment from the tenants is proposed as a way to track industry and cover the progress toward sustainability.

Cecilia concluded that sustainable development can be explained clearly enough to motivate some actors within the park to consider ways in which they can contribute to the over all sustainability of industrial area and local community. A similar condition ensues in which the desire for sustainability suggest responsible corporate activities that will enhance the future of region.

David Pearce and Giles Atkinson in a working paper (CSERGE PA 98-02), "The concept of Sustain development: An Evaluation of its usefulness ten years after Brudtland" referred to sustainable development as being equated with a development path that ensures non-declining per capita well-being ever some time horizon. In a bid to address the issue of how to achieve sustainable development, they employed the augmented Solow model which deals with the widening of the concept of man-made capital to include the skills and knowledge embodied in human capital and natural capital. They also included social capital which addressed the issue of relationship between industrial and government/institutions, stating that for the capital base of sustainable development, we would need a positive technological change, a positive population change and natural asset constancy.

In addition, the concept of weak sustainability was clarified:

Weak sustainability - that all forms of capital are substitutable for each other- and strong sustainability-weak sustainability plus preserved natural capital.

They cited Beckerman's critique which suggested that weak sustainability adds nothing to conventional economic optimality as it precludes a declining path of per capita well being overtime which is not envisaged by conventional optimizaton when translated into rules for maximsing the present value of utility overtime; This problem according to Beckerman has not been really addressed by strong sustainability advocates 
A greater understanding of how technological change is created is vital and that genuine savings natural assets and environmental depreciation also have Implication for sustainability.

They concluded with the statement:

"Nevertheless to the extent that scientific community can offer evidence regarding what constitute natural assets, the Key indicators for an economy will be twofold: are stocks of critical natural assets declining? And are genuine savings rate persistently negative? A positive answer to these questions would be an indication of unsustainability" (David Pearce and Giles Atkinson CSGE PA 98-02)

Jonathan M. Harris (2000) in his paper title basic principles of sustainable Development Employed the Rostow's stages of Economic growth to advance his argument for sustainable Development. He also emphasized the major area of concentration for development purposes over the years which are; industrialization and agriculture, basic needs in the 1970s which included Education, nutrition, health, sanitation and employment

Human Development index (HDI) which uses health and education measured together with Gross Domestic product(GDP), by the 1980s, the focus shifted to "structural adjustment" which included liberalization of trade, eliminating government deficits and parastatals

With significant advancement both in GDP and HDI in most countries, he highlighted two major criticisms in the development records which are:

$\checkmark \quad$ The benefits of development have been distributed unevenly with income inequality remaining persistent and increasing overtime.

$\checkmark \quad$ There have been major negative impacts of development on the environments and on existing social structures He cited the criticism by Richard Nogarrd who sees development as indicative of fundamental Error which is stated as follows:

"Modernism and its more recent manifestation as development have betrayed progress:...... While a few have attained material abundance, resource depletion and environmental degradation now endanger many and threaten the bope of all to come......"

Modernism betrayed progress by leading us into, and preventing us form seeing and addressing interwoven, environmental, organizational and cultural problems

Jonathan defined sustainable development as "the development which meets the need of the present without compromising the ability of the future generation to meet their own needs with particular interest in the three areas of sustainable development which are economic, environmental and social issues.

In the treatment of the economic prospective, he employed the neo-classical perspective which analyses sustainability as the maximization of welfare overtime, which included important elements of human welfare. A related issue he discussed is the operationalisation and conservation of natural capital by adopting a limit to resource consumption for renewable to sustainable yield levels, and for non-renewable to invest its proceeds in renewable capital. In addition to maintain constant per capital stock of natural capital, it would require a stable level of human population.

He referred to Michael Toman Suggestion that the issue of sustainability will be resolved by the neoclassical market efficiency and the adoption of safe minimum standards to protect essential resource and environmental functions. 
In an ecological perspective, sustainability must involve limits on the population and consumption levels and the process that generate variability and novelty-the generation of genetic diversity and the resultant processes of evolution and change in species and ecosystem

Jonathan Harris (2000) noted that advocates of sustainable development recognize social development as an essential part of the parading. The major area of emphasis included. Human Development index per capita GNP/GDP Gender Equity, poverty, e.t.c He concluded by saying that

"true sustainability means a major shift from existing techniques and organization of production (in areas as Agriculture, Energy, industry, renewable resource system) to newer techniques that will practically address the real issues without Jeopardizing the future, but instead, presence it."

\section{A Review of the Plan Implementation of the World Summit on Sustainable Development}

The 'plan of implementation of the world summit on sustainable Development' listed about 170 issues as they affect sustainable development, with the major issues listed as follows:

$\checkmark \quad$ Commitment at all levels to the United Nation Millennium Declaration held in Rio de janeiro in 1992.

The effort will promote the integration of the three components of sustainable development - economic development, social development and environmental protection-as interdependent,and mutually reinforcing pillars. Poverty eradication, changing unsustainable pattern of production and consumption and protecting and managing the natural resource base of economic and social development are overarching objectives and essential requirement for sustainable development.

$\checkmark \quad$ Good governance within each country at all levels sound policies on social environmental and economic issues; democratic institutions responsive to the needs of the people the rule of law; anti- corruption measures; gender equality and an enabling environment for investment as basis for sustainable development; external assistance to individual especially between developed logy to coffer diet and trade and full participation of developing countries in global decision making.

$\checkmark \quad$ Peace, security and respect for human might and fundamental freedoms, including the right to development and ensuring that the benefits of development includes all, especially, the valuable groups women, children. Youths In a bid to eradicate poverty, the function point

$\checkmark \quad$ Access to quality health care services by rural and urban for all person; good education for all children especially primary schooling and all levels of schooling; combat desertification and mitigate the effects of drought, floods; land and natural resource management; increase access to clean driving water and adequate sanitation to improve and protect human health and environment; transfer basic sustainable agricultural techniques and knowledge including natural resource management to small and medium scale for mores, fishes and the rural poor in Developing countries.

Other measures include; improve access to reliable and affordable energy services; strengthen the contribution of industrial development to poverty eradication; 
improve the people living in slums by 2020; eliminates of the worst forms of child labour.

$\checkmark \quad$ Specific actions on consumption and production patterns to achieve sustainable development include from using governments and institutions to the way promote a framework in support of social and economic development policies addressing basic issues such as pollutions, waste, enhancing corporate environmental and social responsibility and accountability,

$\checkmark \quad$ In addition, promotion of a good transport system at all levels; prevent and minimize waste and maximize reuse recycling and use of environmentally friendly alternative materials

$\checkmark \quad$ Specific actions to protecting natural resource base of economic and social development include; Development of strategies to protect the ecosystem; financial and technical assistance to achieve the MDGs on safe drinking water; promote the conservation and management of the oceans; enhance maritime safety candle security land based activities; risk assessment and disaster management promote sustainable tourism including non-consumptive and eco-tourism; preservation of Biological definition introduction of forest management and improvement.

$\checkmark \quad$ To achieve sustainable development in a globalizing world, the course of action suggested include ensuring full participation and equity among all especially developing nations; strengthen the capacities of developing countries to encourage public/private initiatives that enhance the ease of access timeliness and coverage of information on countries; strengthen the regional trade and cooperation agreement

$\checkmark \quad$ To achieve good Health and sustainable Development the specific objective include poverty eradication as to avoid high prevalence of debilating diseases; strengthen the capacity of health care services to all in efficient, accessible and affordable manner; reduction of HIV Prevalence among young men and women aged 15 to -25 in most affected countries by 2005 and globally by 2010 as well as combat malaria, tuberculosis and other diseases; phase out lead in lead-based paints and in other sources of human exposure

$\checkmark \quad$ With particular reference to sustainable Development to different regions, the African perspective include welcoming of New partnership for Africa's Development [NEPAD] and other existing development framework that are owned and driven nationally by African countries and that embodies poverty reduction strategies; provide financial aid Technical support of Africa's effort to implement land and natural resources management practices; mobilize financial and other support to develop and strengthen health systems; promote integrate water resource development and options the upstream and downstream benefits through effective management policies

In addition to enhancing ensuring sustainable development in Africa other measures to be employed include Achieve sound management of chemicals, with particular focus onhazardous chemicals and waste' Bridge the digital divide and create opportunity in terms of access infrastructure and technology transfer and application through integrated activities for Africa; create an existing environment to attract investment; accelerate new and existingprogrammes and projects; support African countries in their efforts to implement the habitat agenda though initiatives to strengthen national, local 
and institutional capacities in sustainable urbanization and local and institutional capacities.

Plan implementation is said to include; the assessment of plans contribution to development process; the extent of consultation among government offices as well as between states and private interest during the formulation stage of a plan. In addition, it involves a cooperation and participation of the various groups/ stakeholders namely planners, policy makers and the society at large.

The world summit on planning for sustainable development adopted the following strategies for the implementation of its objectives; adequate funding of the MDGs through significant increased flow of financial resource to less developed countries in particular capacity-building and information for decision making and scientific capabilities; facilitate greater flow of foreign direct investment so as to support sustainable development activities; including the development of infrastructures of developing countries and enhance the benefits that foreign direct investments provide, recognitionthat a substantial increase in official development assistance and other resource will be required in LEDCs; making full and effective use of assisting financial mechanism and institutions; reduction as debt burden, debt cancellation and other effective mechanism geared to solving debt problems; promotion of public - private partnership to mobilize resources; Build the capacity of commodity dependent countries to diversify export through financial, technical and international assistance for economic diversification and sustainable resource management.

Other strategies include - promote mutual support evens between multilateral trading system and the multilateral environmental agreements; take concerted action against international terrorism; support publicly funded research and development in strategic alliance for the purpose of enhancing research and development to achieve cleaner production and production technologies; provide a wide range of formal and informal continuing education opportunities; integrate sustainable development into education system at all levels of education in order to promote education as key agent for change; Enhance and Accelerate human, instructional and infrastructure capacity in response to specific reeds in LEDCs; Elimination of gender disparity; Encourage further work on indicators for development and strengthen information and statistical and analytical services relevant for sustainable development policies and programmes at all levels.

\section{A Review of the Nigeria Case on Sustainable Development}

Lele (1991) describes sustainable development as "a new way of life and approach to social and economic activities for all societies, rich and poor which is compatible with the preservation the Environment

Sustainable Development in my view could be referred to as efficient management of resources for human survival taking into consideration both the present and future generation.

Specifically, some factors could be identified asobstacles to achieving sustainable development in less Economically Developed Countries (LECDs) like Nigeria?

- The priorities of LEDC governments and individuals are often short term e.g. meeting the basic needs of population today. For example, providing shelter, food, fresh 
running water, education and healthcare. Many LEDCs are experiencing internal conflict/natural disasters and money is spent on the military/disaster relief rather than on these basic needs and longer term sustainable initiatives;

- $\quad$ Corruption makes it difficult to priorities long term issues. Many leader are in office for short periods of time and are changing often;

- Lack of qualified people to develop and implement alternative technologies due to a poor educational system and the "brain drain";

- Lack of education about finite resources. People do not know or understand the implications of over use of resources'

In the light of this challenges, specific areas of sustainable development effect for Nigeria and its implication for general development are as follows:

\subsection{Environmental protection}

Nigeria is a member of international and global community and as such share in the effects of technological advancement specifically environmental management is particularly necessary and its major aim should is to avoid stressing a valued ecosystem beyond the limits of its resilience, stability and carrying capacity (Oyeshola, 2008)

The oil rich regions such as have a greater effect of most of this environmental degradation challenges in areas such as: oil spillage; crude oil content chemical substances as sulphur nitrogen, oxygen as well as hydrocarbon component oil spillage will affect living things comment will life, aquatic life plant life directly indirectly thereby being implications for the bio-diversity of all living things new and in future.

- Gas flaring. These flares contribute to greenhouse gases which contain toxins and therefore, exposes everyone to diseases such as asthma, respiratory illness, cancer and premature deaths .

To combat these particular environmental issues in Nigeria, the investors

We can develop a gas policy which will be favorable to both the population and

- Articulate a national environmental health policy and national health action plan

- Review and harmonise existing health Laws

- $\quad$ Promote safe use of pesticides and other agrochemicals

- Develop a master plan on solid waste management

- Develop environmental health performance indicators

- $\quad$ Bringing pollution and environmental waste under control

- $\quad$ Phase out ozone-depleting substances

- $\quad$ Phase out persistent organic pollutant

- Use alternative Energy services that are more favourable- solar power, wind power and hydro power

- Comply with international standards in controlling and monitoring of environment

- Review the Land policy in Nigeria 
- In recent times, in view of the current flood disasters, there may be the need to come up with policies that address issues such as town planning, deforestation and general waste management.

\subsection{Economic Development}

This involve achieving a balance in all sectors of the Economy in the process of production of goods and services be it agriculture, finance, manufacturing, health, education, e.t.c

The Economic challenge inherent in the Nigeria Economy include issues social such as poverty, low per capital income, inequitable distribution of home, low capital formation, inefficiency in the mobilization of resource, over- dependence on a singular commodity oil-as a major source of income, Unemployment, inflation to mention a few.

To tackle some of these challenges, some measures to be taken include:

- $\quad$ Provision of soft loans to less privileged persons to promote Small and Medium scale Enterprise (SMEs).

- $\quad$ Address the problem of financing the real sector end mobilization of long term savings for investment.

Job training of people in skills relevant to their immediate work environment and rural development should be incorporated.

- $\quad$ Agriculture and food security policies should be enhanced by strengthening research and development to improve production and enhance exportation thereby boosting income.

- Strengthen the regulation and supervisory framework of the financial sector .

- $\quad$ Promotion of indigenous goods and services especially through SMEs.

\subsection{Social Development}

This is set to achieve equity in social issues as education, health politics, social infrastructures, e.t.c

It is reaffirmed that Nigeria in order to achieve any meaningful development must take care of social services of basic education, functional health care, employment for youth, clean water, security of life and properties, and access to quality infrastructures.

To handle some of these issues, giving the nature of their externality, the reasonability of government cannot be overemphasized.

To achieve this social development, the Nigeria government in addition to existing policies can adopt the following.

- $\quad$ Creation of new employment opportunities for young school learners and rural dwellers.

- $\quad$ Strengthen institutions of governance at all levels including adequate attention to human right and conflict prevention.

- $\quad$ Provision of basic social and essential sources education, health, clean water, e.t.c

- Maintenance of Existing structures and creation of new ones where they are needed 


\section{Conclusion}

In a bid to address the challenge of sustainable development globally, and particularly in Nigeria, all available means must be employed to tackle related problems of the environment as well as economic and social issues. This can be achieved by taking a conscious step towards the achievement of the goal of sustainable development given as stated in section 5 above.

In addition, the issue of sustainability must be a concern to all parastatals (public and private) and individuals. This will require educating everyone on the need for sustainable development and as a result walk towards its actualization. Besides sanctions for erring persons must be ensured if the success of the process of sustainable development is to be attained

Finally, policies that will promote sustainability should be in place by the government of individual countries, which are consistent with international policies, in order to achieve an overall global sustainable development.

Note: It must be noted that to further studies on sustainable development could be examined. With the use of statistical and empirical analysis on previous trends and current issues facts surrounding issues on sustainability will be clearly spelt out, thereby, enhancing objectivity in policy making.

\section{References}

Atkinson, G. Doubourg, W.R. Hamilton, K. Munasinge, M Pearce,D.W. and Young C.E.F. (1997), "Measuring Sustainable Development". Macroeconomics and the environment; Cheltenham

B. L. Mathur (2002). "Economic Planning and Development theory and practice". Sublime publications japer, India

Cecelia Haskins (2009). "Using the concept of sustainable development to encourage corporate responsibility in small enterprise". Norwegian University of science and Technology Trondheim, Norway

David Pearce and Giles Atkinson, CSERGE Working paper PA 98-02, “THE CONCEPT OF SUSTAINABLE Development.An evaluation of its usefulness. Ten years after Brundtland", Centre for social and Economic Research on the Global Environment University college London and University of East Anglia.

"Definitions on The concept of sustainable development". ibgeog.wikispaces.com/.../concept+of+sustainable+development

Jonathan M. Harris (2000), "Basic Principles of sustainable Development". Tufts University Medford MA 02155, USA. Global Development and Environmental institute Working paper 00-04

Lele S.M (1991). "Sustainable Development A critical Review on world Development (1991): Plan of implementation of the world summit on sustainable development at the united Nation" Conference; WWW. UN. Org/ ... /WSSD_PlanImpl- pdf

National Bureau of Statistics (2011). "Nigerian Poverty Profile, 2010". National Bureau of Statitics. 
Odermerho Francais (1993). "Flood Control in a Third World City: Benin City Nigeria- Some Environmental and Policy Issues". Geo Journal 29.4 371-376, Kluwer Academic Publishers

Oyeshola Dokun, O.P. (2008), Sustainable Development - Issues and challenges for Nigeria.

Todaro M. P. and Smith S. C. (2011). "Economic Development". Pearson Education Limited, Eleventh edition 